
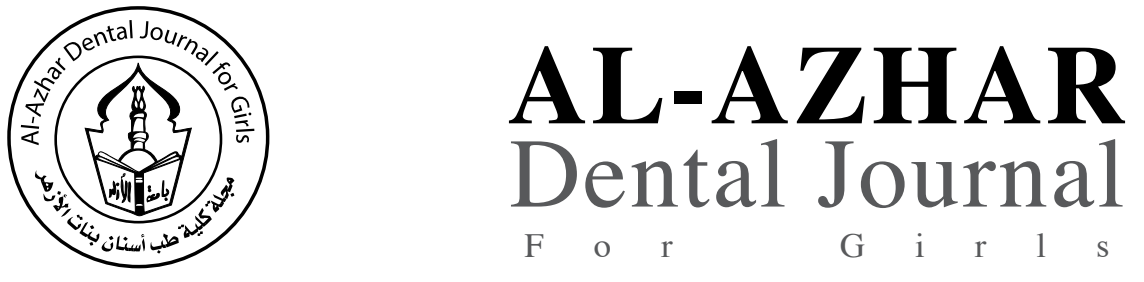

The Official Publication of The Faculty of Dental Medicine For Girls, Al-Azhar University Cairo, Egypt.

ADJ-for Grils, Vol. 4, No. 2, April (2017) — PP. 111:120

\title{
Changes in Smile Proportions Concomitant to Extraction and Non- Extraction Orthodontia (A Comparative Study)
}

\author{
Marwa M. Hassan $^{(1)}$, Samir A. Ibrahim ${ }^{(2)}$ and Ahmad E. Salama ${ }^{(3)}$
}

Codex : 13/1704

dentaljournal.forgirls@yahoo.com

Paper extracted from master thesis entitled " Changes in Smile Proportions Concomitant to Extraction and Non- Extraction Orthodontia (A Comparative Study)”

\begin{abstract}
Objective: An attractive, well-balanced smile is a paramount treatment objective of modern orthodontic therapy. The purpose of this study was to compare changes in smile proportions among extraction and non-extraction therapy cases and to correlate them with the accompanying hard and soft tissue changes. Material and Methods: A sample of 24 patients with an age range of 14.3-24.9 years, requiring fixed orthodontic treatment was divided into group I (extraction therapy cases) and group II (nonextraction therapy cases). Dentofacial characteristics of the 2 groups were obtained from close up smile photographs and lateral cephalometric analyses before and after treatment. independent student " $\mathrm{t}$ " test to compare between both groups before and after treatment, Paired student " $t$ " test to evaluate the change within the same group and Pearson's correlation analysis to evaluate correlations between selected parameters. Results: After treatment, maxillary incisor display showed significant increase in the nonextraction group also, maxillary gingival display showed significant increase in the extraction group $(\mathrm{P} \leq 0.05)$. When the two groups were compared, after treatment, the extraction group showed significant higher values in the posterior corridor ratio and maxillary gingival display $(\mathrm{P} \leq 0.05)$. The posterior corridor ratio was negatively correlated with lower anterior facial height $(\mathrm{r}=-0.579)$.The amount of incisor display during smile was positively correlated with the inclination of maxillary incisors in relation to the skull base $\mathrm{U} 1 / \mathrm{SN}\left(^{\circ}\right)(\mathrm{r}=0.499)$ and with maxillary incisors protrusion measured as U1/NA distance $(r=0.676)$. Conclusion: the results revealed that the extraction therapy cases showed higher values in the posterior corridor ratio and maxillary gingival display than the non extraction therapy cases. The significant relationship of incisor protrusion and inclination with the amount of incisor display and the significant relationship of lower anterior facial height with the posterior corridor ratio must be considered when plan-

ning orthodontic treatment
\end{abstract}

\section{Orthodontics, Smile, \\ Effect, Extraction \\ KEYWORDS}

1. BDS 2006, Faculty of Oral and Dental Medicine. Ain Shams University.

2. Professor of Orthodontics, Head of orthodontic department -Faculty of Dental Medicine for Girls- Al-Azhar University.

3. Professor of Orthodontics, Orthodontic department -faculty of Dental Medicine for Girls Al-Azhar University 


\section{INTRODUCTION}

Cosmetic dentistry has been interested in smile esthetics. Recently, the topic has become important for orthodontists as more orthodontic patients evaluate the outcome of treatment by the overall enhancement in their smiles and facial appearance ${ }^{(1)}$. Although orthodontic treatment is based primarily on occlusal relationships, greater attention is now paid to enhancing dentofacial characteristics to produce optimal facial esthetics ${ }^{(2)}$.

It seems worthwhile to outline the common denominators of an esthetically pleasing smile, which is often a primary reason for seeking orthodontic care. The literature contains noteworthy studies ${ }^{(3-10)}$ describing the esthetic elements of the dentition and the surrounding soft tissues during smiling that can be evaluated on a 3-dimensional canvas. instructive data ${ }^{(11-12)}$ about published about the 4-dimensional dynamic smile analysis, and relevant treatment strategies. It was suggested that, in addition to the frontal, oblique, sagittal; the orthodontist should add another dimension - time-in evaluating smiles (how smiles change over time because of aging). Later on, smile esthetics ${ }^{(13)}$ was segregated in this frontal view into 3 distinct components; the lip framework, the gingival tissues, and the dentition.

Extraction treatment has long been accused of having deleterious effects on the smile ${ }^{(14)}$. It is suspected arch width reduction by premolar extractions that decreases the buccal corridor ratio and leads to black triangles at the corners of the mouth during smiling. Another study ${ }^{(15)}$ concluded that variables related to the buccal corridor or other measures of the relationship between the widths of the dentition and of the mouth during a smile showed no relationship to extraction esthetics. Furthermore, 2 other studies ${ }^{(16,17)}$ supported these views by comparing arch widths after extraction and nonextraction treatment in study casts. However, first speculation team (18) argued that plaster models cannot tell us about human faces or the lip support they do or do not provide.
Historically, the former investigations concerning the effects of the extraction protocol depended either on the cephalometric analysis and cast analysis or on photographic analysis. Similarly, Specific hard and soft tissue features of the smile have been studied extensively in the literature but without examination of the relationship between their etiology and smile esthetics.

The aim of this study was not only to compare the changes in smile proportions concomitant to extraction and non extraction orthodontic treatment but also to study the factors that might influence the changes observed with such treatment

\section{SUBJECTS AND METHODS}

Study sample: the study was performed on 24 subjects. All subjects were selected and treated at the out-patient orthodontic clinic of the Faculty of Dental Medicine, Al-Azhar University; Girl's branch. The criteria for subjects selection were as follow:

- No previous extraction of permanent dentition or congenitally missing teeth.

- Female patients to exclude the effect of gender difference.

- No severe craniofacial deformations.

- No previous orthodontic treatment.

- Normal clinical crown length.

\section{Patient grouping:}

The patients were divided into:-

Group (I): consisted of 12 non-extraction therapy patients. The age range was $17.8 \pm 3.3$ years.

Group (II): consisted of 12 extraction therapy patients. The age range was $19.6 \pm 5.3$ years.

\section{Records:}

In addition to the routine orthodontic records, pre and post treatment standardized digital close up 
smile photographs and intraoral frontal photograph were taken and used in collecting the data in addition to cephalometric data.

\section{1- The photographic records}

All the photographs were taken by the same photographer by the same camera (Canon EOS 550D (Tokyo, Japan), SLR camera) under standardized environment. The patient was asked to smile as broad as possible and to repeat this smile until the photographer was ascertained of the reproducibility of the smile. The photographs were transferred to computer software Adobe Photoshop. (CS middle east version) and they were cropped to the size of 6 $\times 3$ inches. The ruler in the same software was used to obtain all measurements for this study before and after treatment. Averages of 2 measurements made by the same investigator were taken with two weeks interval. To check the magnification error, the width of the upper right central incisor at the interdental papilla level was measured on the cast and compared to the corresponding measurement on the photographs.

\section{Definitions of the measured smile parameters:} Figure (1)

1. Smile index ${ }^{(2)}$ : Smile width divided by the interlabial gap

2. Maxillary intercanine width: the distance from the distal aspect of the right canine to the distal aspect of the left canine.
3. Width of all visible maxillary teeth: the distance from the distal aspect of the most posterior visible tooth on the right to the most posterior visible tooth on the left side of the maxilla

4. Buccal corridor ratio ${ }^{(21)}$ : the difference between maxillary intercanine width and inner commissural smile width divided by inner commissural smile width

5. Posterior corridor ratio ${ }^{(21)}$ : the difference between visible maxillary dentition width and inner commissural smile width divided by inner commissural smile width.

6. Maxillary gingival display ${ }^{(22)}$ : the amount of maxillary gingival exposure between inferior border of upper lip and marginal gingiva of maxillary central incisors

7. Maxillary incisor display ${ }^{(23)}$ : height of central incisor during smiling divided by actual height of central incisor

8. Upper vertical lip thickness: the vertical distance from the most superior peak of the vermilion border of the upper lip to the most inferior portion of the tubercle of the upper lip

9. Lower vertical lip thickness: The vertical distance from the deepest midline point on the superior margin of the lower lip to the most inferior portion of the vermilion border of the lower lip.

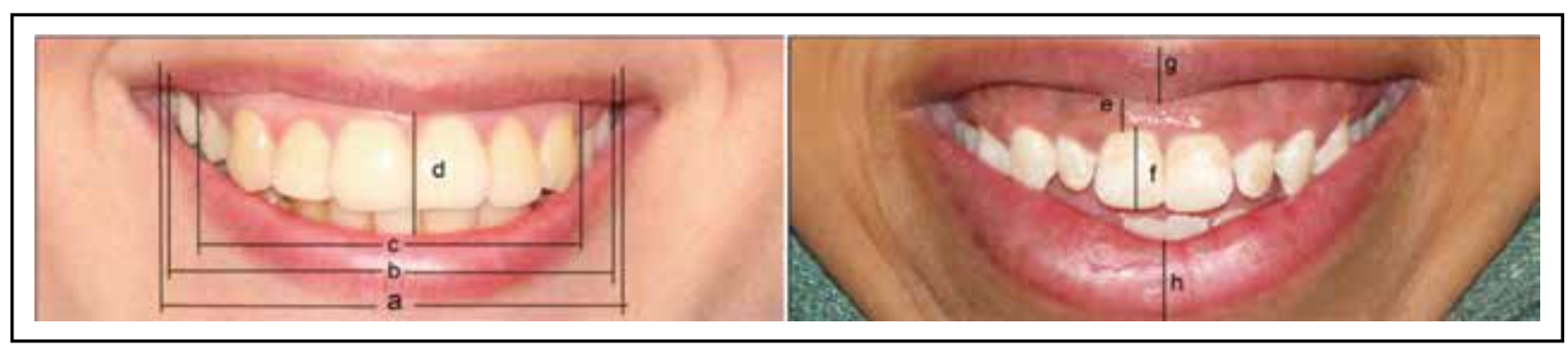

Fig. (1) A showing the smile index (smile width (a) /interlabial gap (d)), Buccal corridor ratio: smile width (a) - maxillary intercanine width (c)/ smile width (a) while posterior corridor ratio (smile width (a)- width of all visible maxillary teeth (b)/ smile width (a). Figure 1.B showing maxillary gingival display (e), maxillary incisor display (f), upper vertical lip thickness (g), and lower vertical lip thickness (h). 


\section{2- The lateral cephalometric radiographs}

All the radiographs were taken by the same digital machine. The cephalometric films were traced on 0.003 inch thickness translucent acetate tracing paper using 0.35 pencils before and after treatment. All the radiographs were traced by the same investigator twice with an interval of two weeks; the mean of the two measurements was recorded.

\section{Measurements on lateral cephalometrics radiographs}

Six angular ANB $\left({ }^{\circ}\right), \mathrm{U} 1-\mathrm{SN}\left({ }^{\circ}\right)$, UI-NA $\left(^{\circ}\right)$, IMPA $\left({ }^{\circ}\right)$, N-L $\left(^{\circ}\right), \mathrm{M}-\mathrm{L}\left({ }^{\circ}\right)$ ) and six linear ( NAMe, ANS-Me , U1- Na , U1 - PP plane , upper and lower lips to B-line) measurements were derived for conventional cephalometric analysis ${ }^{(22-27)}$ for the assessment of skeletal, dental and soft tissue changes before and after treatment

The Statistical tests applied to the data collected included independent student " $t$ " test to compare between both groups before and after treatment,
Paired student " $t$ " test to evaluate the change within the same group and Pearson's correlation analysis to evaluate correlations between selected parameters. Differences were considered statistically significant when $\mathrm{p} \leq 0.05$.

\section{RESULTS}

\section{Photographic changes}

After treatment and according to the statistical data, smile index, buccal corridor ratio and posterior corridor ratio showed negligible differences according to the statistical tests in both groups tables $(1,2,3)$ while the nonextraction group showed significant increase in maxillary incisor display table (5). Also, the extraction group showed significant increase in maxillary gingival display table (4) (P $\leq 0.05)$. When the two groups were compared, after treatment, the extraction group showed significant higher values in the posterior corridor ratio and maxillary gingival display $(\mathrm{P} \leq 0.05)$

Table (1) Mean and St Dev, $t$ and $P$ values of the smile index before and after treatment in both groups

\begin{tabular}{|c|c|c|c|c|c|c|}
\hline \multirow{2}{*}{ Smile index } & \multicolumn{2}{|c|}{ Before } & \multicolumn{2}{|c|}{ After } & \multirow{2}{*}{ Paired " $\mathrm{t}$ " } & \multirow{2}{*}{ Probability } \\
\hline & Mean & St Dev & Mean & St Dev & & \\
\hline Group 1 & 6.11 & 1.75 & 6.06 & 1.28 & 0.158 & $0.439 \mathrm{NS}$ \\
\hline Group 2 & 5.32 & 1.19 & 5.16 & 1.04 & 0.670 & $0.260 \mathrm{NS}$ \\
\hline Unpaired " $\mathrm{t}$ " & \multicolumn{2}{|c|}{1.167} & \multicolumn{2}{|c|}{1.690} & & \\
\hline Probability & \multicolumn{2}{|c|}{$0.130 \mathrm{NS}$} & \multicolumn{2}{|c|}{$0.055 \mathrm{NS}$} & & \\
\hline
\end{tabular}

Table (2) Mean and St Dev, $t$ and $P$ values of the Buccal corridor ratio before and after treatment in both groups

\begin{tabular}{|c|c|c|c|c|c|c|}
\hline \multirow{2}{*}{ Buccal corridor ratio } & \multicolumn{2}{|c|}{ Before } & \multicolumn{2}{|c|}{ After } & \multirow{2}{*}{ paired " $\mathrm{t}$ " } & \multirow{2}{*}{ Probability } \\
\cline { 2 - 5 } & Mean & St Dev & Mean & St Dev & & \\
\hline Group 1 & 0.29 & 0.07 & 0.27 & 0.07 & 1.608 & $0.073 \mathrm{NS}$ \\
\hline Group 2 & 0.30 & 0.06 & 0.28 & 0.08 & 0.733 & $0.241 \mathrm{NS}$ \\
\hline Unpaired "t" & \multicolumn{2}{|c|}{0.441} & \multicolumn{2}{|c|}{0.439} & & \\
\hline Probability & \multicolumn{2}{|c|}{$0.332 \mathrm{NS}$} & \multicolumn{2}{|c|}{$0.333 \mathrm{NS}$} & & \\
\hline
\end{tabular}


Table (3) Mean and St Dev, $t$ and $P$ values of the posterior corridor ratio before and after treatment in both groups

\begin{tabular}{|c|c|c|c|c|c|c|}
\hline \multirow{2}{*}{ Posterior corridor ratio } & \multicolumn{2}{|c|}{ Before } & \multicolumn{2}{|c|}{ After } & \multirow{2}{*}{ Paired "t" } & \multirow{2}{*}{ Probability } \\
\hline & Mean & St Dev & Mean & St Dev & & \\
\hline Group 1 & 0.14 & 0.14 & 0.09 & 0.04 & 1.367 & $0.104 \mathrm{NS}$ \\
\hline Group 2 & 0.12 & 0.06 & 0.26 & 0.30 & 1.606 & $0.071 \mathrm{NS}$ \\
\hline Unpaired " $\mathrm{t}$ " & \multicolumn{2}{|c|}{0.440} & \multicolumn{2}{|c|}{1.774} & & \\
\hline Probability & \multicolumn{2}{|c|}{$0.333 \mathrm{NS}$} & \multicolumn{2}{|c|}{$0.047 *$} & & \\
\hline
\end{tabular}

Table (4) Mean and St Dev, $t$ and $P$ values of the maxillary gingival display before and after treatment in both groups

\begin{tabular}{|c|c|c|c|c|c|c|}
\hline \multirow{2}{*}{$\begin{array}{c}\text { Maxillary } \\
\text { Gingival Display }\end{array}$} & \multicolumn{2}{|c|}{ Before } & \multicolumn{2}{c|}{ After } & \multirow{2}{*}{ paired "t" } \\
\cline { 2 - 7 } & Mean & St Dev & Mean & St Dev & 0.865 & 0.206 NS \\
\hline Group 1 & -0.75 & 1.91 & -0.35 & 0.81 & 3.178 & $0.006 * *$ \\
\hline Group 2 & -0.36 & 1.26 & 0.55 & 1.21 & \\
\hline Unpaired "t" & \multicolumn{2}{|c|}{0.524} & \multicolumn{2}{|c|}{1.880} & & \\
\hline Probability & \multicolumn{2}{|c|}{$0.303 \mathrm{NS}$} & \multicolumn{2}{|c|}{$0.039 *$} & & \\
\hline
\end{tabular}

Table (5) Mean and St Dev, $t$ and $P$ values of the maxillary incisor display before and after treatment in both groups

\begin{tabular}{|c|c|c|c|c|c|c|}
\hline \multirow{2}{*}{$\begin{array}{c}\text { Maxillary incisor } \\
\text { display }\end{array}$} & \multicolumn{2}{|c|}{ Before } & \multicolumn{2}{c|}{ After } & \multirow{2}{*}{ paired "t" } & Probability \\
\cline { 2 - 7 } & Mean & St Dev & Mean & St Dev & 2.715 & $0.013 *$ \\
\hline Group 1 & 0.83 & 0.15 & 0.93 & 0.07 & 0.559 & 0.295 NS \\
\hline Group 2 & 0.94 & 0.10 & 0.96 & 0.04 & \\
\hline Unpaired "t" & 1.902 & 0.908 & & \\
\hline Probability & $0.037 *$ & & & & \\
\end{tabular}

\section{Cephalometric Changes}

After treatment and according to the statistical data, the nonextraction group showed significant increase in, ANS/Me, IMPA and U1/NA distance. In the extraction group, only NA/Me showed significant post treatment increase but U1/SN $\left(^{\circ}\right)$, IMPA $\left({ }^{\circ}\right)$, U1- Na distance and the upper and lower lips to B-line distance showed significant decrease $(\mathrm{P}$ $\leq 0.05)$. When the two groups were compared, the two groups presented similar hard tissue facial and dental characteristics before treatment yet, the soft tissue facial characteristics showed more protrusive lower lips in the extraction group in relation to B-line. After treatment, the two groups were still almost similar except for lower values in IMPA and $\mathrm{U} 1 / \mathrm{NA}$ distance in the extraction group $(\mathrm{P} \leq 0.05)$.

\section{Structural Correlations}

According to Pearson correlation coefficients, only posterior corridor ratio of the transverse 
characteristics of the smile was related to the cephalometric measurement, while of the vertical smile characteristic, maxillary incisors display were related to certain cephalometric measurements. The posterior corridor ratio was negatively correlated with lower anterior facial height $(r=-0.579)$ figure (2).The amount of incisor display during smile was positively correlated with the inclination of maxillary incisors in relation to the skull base $\mathrm{U} 1 / \mathrm{SN}\left(^{\circ}\right)(\mathrm{r}=0.499)$ figure $(3)$ and with maxillary incisors protrusion measured as U1/NA distance $(r=0.676)$ figure (4).

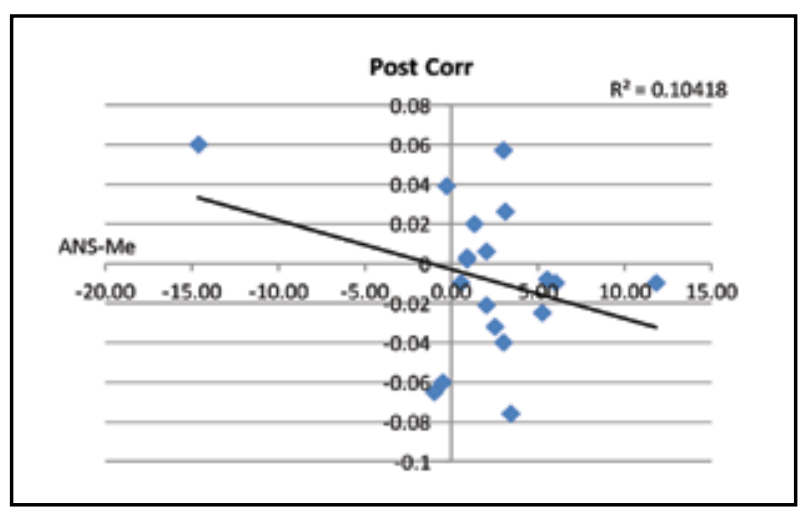

Fig. (2) Showing significant negative correlation between posterior corridor ratio and lower anterior facial height $(\mathrm{r}=-0.579)$

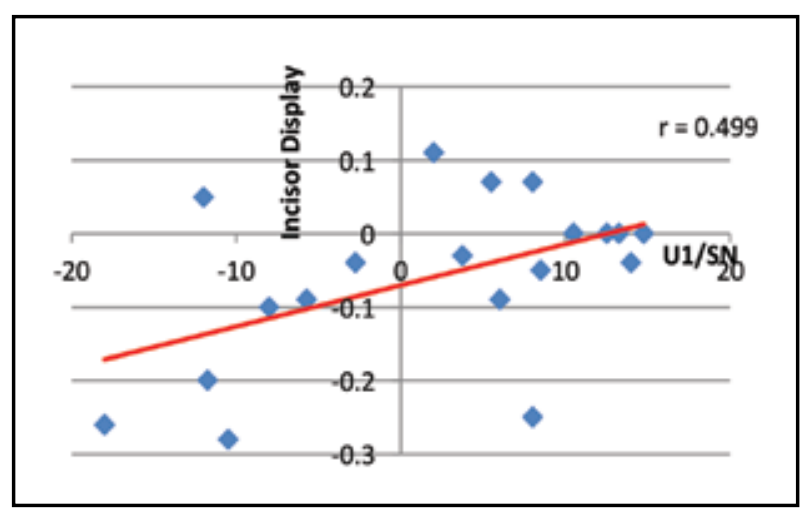

Fig. (3) Showing significant positive correlation between incisor display and U1-SN angle $(r=0.499)$

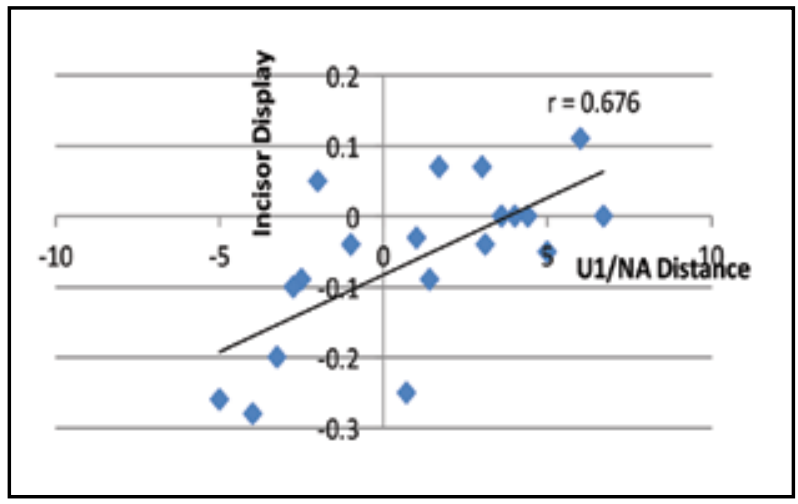

Fig. (3) Showing significant positive correlation between incisor display and U1-NA distance $(r=0.676)$.

\section{DISCUSSION}

\section{Photographic changes}

The concept of a prevailing arch narrowing after premolar extraction treatment investigations cannot be supported by the results of the present study. This finding agreed with some investigators ${ }^{(28,29)}$ and is conflicting with others ${ }^{(15,30)}$. These conflicting findings can be attributed to the wide diversity in the pretreatment degree of crowding and in the position of the malposed canines in the sample groups. Moreover, the buccal corridor ratio -calculated by dividing the difference between smile width and maxillary intercanine arch width by smile width- did not show any statistically significant differences both within each group or inbetween the two groups before and after treatment This is in accordance with the findings of previous investigations ${ }^{(15,21,31,32)}$.

The posterior corridor ratio showed nonsignificant changes after treatment in both groups. After treatment, the extraction group showed higher values in contrary to the results of previous two investigations ${ }^{(15,21)}$ which showed nonsignificant change between the two groups. This confliction may be attributed to the difference in the amount of anchorage needed in the different treatments planes designed individually for each patient in the samples of all the investigations involved in this topic. 
For example, the apparent narrowing of the arch might be due to the forward movement of posterior teeth during space closure that places them in the narrower anterior part of the arch rather than real narrowing in the arch posteriorly. This difference in the post treatment posterior corridor ratio, although probably clinically noticeable, might not be esthetically objectionable, given the benefits of resolved crowding and protrusion.

The maxillary gingival display was significantly changed only in the extraction group. After treatment, there was statistically significant increase in maxillary gingival display within the extraction group. The extraction group showed significant increase in maxillary gingival display when compared to the non extraction group. The increased maxillary gingival display might be explained by the extrusive component involved in retraction mechanics of extraction therapy.

Maxillary incisor display showed to be of lower values in the non extraction group before treatment. With treatment, there was significant increase in the non extraction group and the difference between both groups became not significant after treatment.

\section{Cephalometric Changes}

Before treatment, the two groups presented similar hard tissue facial and dental characteristics. The recorded measurements denoted no significant differences between the two groups. The soft tissue facial characteristics showed more protrusive lips in the extraction group particularly the lower lip. This is in accordance with the observations of one investigation ${ }^{(37)}$ which pointed out that lip profile is only partly determined by the characteristics of the underlying hard tissues. After treatment, the two groups were still almost similar with only three significant differences, the IMPA, the U1- NA distance

Considering the teeth, both the IMPA and the U1- NA distance were significantly different within the same group. The difference between the two groups was also significant with the higher values present in the nonextraction group. The treatment objective for these patients regarding the incisor position was to relieve any crowding, to enhance their esthetics and to place these teeth in a stable position on their bony bases. The lower incisors were retracted in the extraction group and protruded in the non extraction group. The findings of the present study are in accordance with previous investigations ${ }^{(39,40)}$. However, it is in disagreement with other studies $^{(21,41)}$. One of which ${ }^{(41)}$ reported that the lower incisor in the extraction group was retracted during treatment, whereas no change occurred in the nonextraction group. The investigators stated that this different incisor change during treatment offsets the pretreatment differences in lower-incisor position between groups so that after treatment, the incisor position was the same in each group. On the other hand, the other investigations (21) compared only the post treatment results of both groups and did not include the pretreatment readings of the upper and lower incisor position. In the current study, the pretreatment sample characteristics showed almost similar incisor positioning in both the extraction and nonextraction groups. It is reasonable to assume that the difference in extraction and nonextraction mechanics and space closure between the two conditions would be reflected in the corresponding differences seen in their post-treatment lower-incisor position.

The upper incisors angulation and protrusion decreased significantly in the extraction group. In the non extraction group, there was slight proclination. This is clearly occurred as a result of the clinician's intention of solving the crowding problems of the upper arc. Surprisingly, one later study (42) found that no retraction had occurred following extraction and explained that the patients selected for their study had $7 \mathrm{~mm}$ or more of crowding, and as such, there was no or minimal extraction space left for incisor retraction after crowding was resolved. 


\section{Structural Correlations}

Of the smile parameters that were affected by extraction treatment, two parameters were correlated with the underlying hard and soft tissue characteristics namely posterior corridor ratio, the incisor display. Unfortunately, little literature investigating this correlation was found.

One of which is a study ${ }^{(46)}$ which investigated which hard and soft tissue factors are related with the amount of buccal corridor space during smiling and stated that the buccal corridor is a multifactorial phenomenon and to control the amount of buccal corridor area for achieving a better esthetic smile, it is necessary to observe the vertical pattern of the face. A more recent study ${ }^{(47)}$ analyzed smile in different facial patterns and investigated its correlation with underlying hard tissues and concluded that posterior corridor in vertical facial growth pattern individuals was found to be significantly less when compared with average facial growth pattern individuals.

Agreeing with the previous two studies, the present study showed that the posterior corridor ratio was negatively correlated with lower anterior facial height as measured from ANS to Me. However, there was no significant correlation to upper facial height. One possible reason could be its relationship with the activities of the muscles of the lips which are only present in the lower half of the face. Hence it can be said that a longer face has lesser buccal corridor area. Furthermore, it was found that ${ }^{(12)}$ a patient with a retrusive maxilla can have large buccal corridors. Although the maxilla is of normal width, the buccal corridors might appear prominent because the wider portion of the dental arch is more posterior relative to the anterior oral commissure. That concept was tested and no correlation was found between the size of the buccal corridors and the position of the maxilla relative to the cranial base

The amount of upper incisor display during smile and conversation is one of the most decisive components in aesthetic judgment hence, the clinician must be aware of the controllable variables during treatment planning. One investigation ${ }^{(48)}$ found that the amount of upper incisor display during posed smile was positively correlated with anterior maxillary height. In addition to this parameter, another one ${ }^{(49)}$ found that maxillary incisor exposure as measured as the vertical distance from the inferior border of the upper lip to the incisal edge of the maxillary central incisors, had a positive correlation with the skeletal vertical dimension, as measured from nasion to menton and from anterior nasal spine to menton.

For the present study, it was found that neither the incisal nor the gingival display was correlated with the skeletal vertical dimension. These results agree with the results of one comprehensive study $\left.{ }^{20}\right)$ which found that the incisogingival display could not be correlated with the skeletal vertical dimension, as measured from nasion to menton and from anterior nasal spine to menton. The result of the present study and that of the later study ${ }^{(20)}$ is consistent with many investigations ${ }^{(7,50-53)}$ which suggested that the vertical maxillary excess is only one etiologic factor that contributes to a gummy smile, which occurs when excessive gingival tissue is exposed during smiling.

Results of this study showed that the maxillary incisors display was correlated with maxillary incisors angulation and protrusion agreeing with the results of these two investigations ${ }^{(52),(21)}$. Increasing or decreasing the U1-SN angle beyond the average normal range would cause smile esthetics to deteriorate. For instance, the use of a high-torque bracket system particularly in nonextraction treatment with anterior crowding and initial tooth torques that are close to the desired finished angles would be inappropriate ${ }^{(54)}$. Overexpansion of the maxillary dental arch with increased maxillary incisor torque will reduce incisor display. If a patient shows less than $75 \%$ of the central incisor crowns at smile, tooth display is considered inadequate ${ }^{(5)}$. However, inadequate torque of both the maxillary and mandibular incisors can also result in undesirable effects regardless of the treatment modality ${ }^{(21)}$. 


\section{CONCLUSIONS}

Within the limits of this study, the following conclusions can be withdrawn:-

1. There was no significant treatment effect in the extraction group on smile index, buccal corridor ratio, and posterior corridor ratio. While there was significant increase in the maxillary gingival display

2. There was significant increase in maxillary incisor display in non-extraction cases.

3. There was significant difference in average post-treatment maxillary gingival display and posterior corridor ratio between extraction and non-extraction cases.

4. There was negative correlation between posterior corridor ratio and lower anterior facial height as measured from ANS to Me.

5. There was positive correlation between the amount of incisor display during smile with the inclination of maxillary incisors in relation to the skull base U1/SN $\left(^{\circ}\right)$ and with maxillary incisors protrusion measured as U1/NA distance.

\section{REFERENCES}

1. Havensa D, McNamara JA , Jr b, Lauren M. Siglerc LM and Baccettid The role of posed smile in overall facial esthetics. Angle Orthod. 2010; 80:322-8.

2. Sarver DM. The importance of incisor positioning in the esthetic smile: The smile arc. Am J Orthod Dentofac Orthop. 2001; 120: 98-111.

3. Peck S and Peck L. Selected Aspects of the Art and Science of Facial Esthetics. Semin. Orthod. 1995; 1: 105-26.

4. Rigsbee OH III, Sperry TP and BeGole EA. The influence of facial animation on smile characteristics. Int J Adult Orthod Orthognath Surg. 1988; 3:233-9.

5. Morley J and Eubank J. Macroesthetic elements of smile design, JADA. 2001; 132:39-45.

6. Tjan AH, Miller GD and The JG. Some esthetic factors in a smile. J Prosthet Dent. 1984; 51: 24-8.

7. Hulsey CM.An esthetic evaluation of lip-teeth relationships present in the smile. Am J Orthod. 1970; 57: 132-44.
8. Wong NK, Kassim AA and Foong KW. Analysis of esthetic smiles by using computer vision techniques. Am J Orthod Dentofac Orthop. 2005; 128: 404-11.

9. Parekh S, Fields HW, Beck FM and Rosenstiel SF. The acceptability of variations in smile arc and buccal corridor space. Orthod Craniofac Res. 2007; 10: 15-21.

10. Pinho S, Ciriaco C, Faber J and Lenza M. Impact of dental asymmetries on the perception of smile esthetics. Am J Orthod Dentofac Orthop. 2007; 132:748-53.

11. Ackerman J, Ackerman MB, Brensinger CM and Landis JR. A morphometric analysis of the posed smile. Clin Orthod Res. 1998; 1: 2-11.

12. Sarver DM and Ackerman MB. Dynamic smile visualization and quantification: Part 2. Smile analysis and treatment strategies. Am J Orthod Dentofac Orthop. 2003; 124:116-27.

13. Sharma PK and Sharma P. Dental Smile Esthetics: The Assessment and Creation of the Ideal Smile Assessment of ideal smile. Semin Orthod. 2012; 18: 193-201.

14. Dierkes JM. The beauty of the face: an orthopedic perspective. J Am Dent Assoc. 1987;(Special Issue)89E-95E

15. Johnson DK and Smith RJ. Smile esthetics after orthodontic treatment with and without extraction of four first premolars. Am J Orthod Dentofac Orthop. 1995; 108: $162-7$.

16. Gianelly AA.Arch width after extraction and nonextraction treatment. Am J Orthod Dentofac Orthop. 2003; 123: 25-8.

17. Kim E and Gianelly AA. Extraction vs nonextraction: arch widths and smile esthetics. Angle Orthod. 2003; 73: 354-8.

18. Spahl TJ. Premolar extractions and smile esthetics. Am J Orthod Dentofac Orthop. 2003; 124:16A-17A.

19. Moorrees CF. A. Natural head position - a revival. Am J Orthod Dentofac Orthop. 1994 ; 105:512-3.

20. McNamara L, McNamara JA Jr, Ackerman MB and Baccetti T. Hard- and soft-tissue contributions to the esthetics of the posed smile in growing patients seeking orthodontic treatment. Am J Orthod Dentofac Orthop. 2008; 133: 491-9

21. Isiksal E, Hazar S and Akyalçınc S. Smile esthetics: Perception and comparison of treated and untreated smiles. Am J Orthod Dentofac Orthop. 2006; 129: 8-16.

22. . Steiner CC. Cephalometrics for you and me. Am J Orthod. 1953; 39: 729-55.

23. Steiner CC. Cephalometrics in clinical practice. Angle Orthod. 1959; 29: 8-29.

24. Ricketts RM. Esthetic, environment and the law of lip relation. Am J Orthod. 1968;54(4):272-89. 
25. Burstone CJ. Lip posture and its significance in treatment planning. Am J Orthod. 1967;53:262-84.

26. McNamara JA Jr. A method of cephalometric evaluation. Am J Orthod. 1984; 86: 449- 69.

27. Tweed $\mathrm{CH}$. The Frankfort mandibular incisor angle in orthodontic diagnosis, treatment planning and prognosis. Angle Orthod. 1954; 24: 121- 69.

28. Paquette DE, Beattie JR and Johnston LE. A long-term comparison of nonextraction and premolar extraction edgewise therapy in "borderline" Class II patients. Am J Orthod Dentofac Orthop. 1992; 102: 1-14.

29. Akyalcin S, Erdinc AE, Dincer B, and Nanda RS. Do long term changes in relative maxillary arch width affect buccalcorridor ratios in extraction and nonextraction treatment? Am J Orthod Dentofac Orthop. 2011;139:356-61

30. Luppanapornlarp S and Johnston LE Jr. The effects of premolar-extraction: a long-term comparison of outcomes in "clear-cut" extraction and nonextraction Class II patients. Angle Orthod. 1993; 63: 257-72.

31. . Ghaffar F and Fida M. Effect of extraction of first four premolars on smile aesthetics. Eur J Orthod. 2011; 33:679-83.

32. Meyer AM, Woods MG,b and Mantonc DJ. Maxillary arch width and buccal corridor changes with orthodontic treatment. Part 1: Differences between premolar extraction and nonextraction treatment outcomes. Am J Orthod Dentofac Orthop. 2014;145:207-16.

33. Perkins RA and Staley RN. Change in lip vermilion height during orthodontic treatment. Am J Orthod Dentofac Orthop. 1993;103:147-54.

34. Mirabella D, Bacconi S, Gracco A, Lombardo L and Siciliani G. Upper lip changes correlated with maxillary incisor movement in 65 orthodontically treated adult patients. World Journal of Orthodontics . 2008; 9 337-48.

35. Rains MD and Nanda R. Soft tissue changes associated with maxillary incisor retraction. Am $\mathrm{J}$ Orthod. 1982;74:396-404.

36. Trisnawaty N, Ioi H, Kitahara T, Suzuki A and Takahashi I. Effects of extraction of four premolars on vermilion height and lip area in patients with bimaxillary protrusion. Eur J Orthod 2012; 9; [Epub ahead of print]

37. Burstone CJ. Lip posture and its significance in treatment planning. Am J Orthod. 1967; 53: 262-84.

38. Basciftci FA and Usumez S. Effects of Extraction and Nonextraction Treatment on Class I and Class II Subjects. Angle Orthod. 2003;73:36-42.

39. Nanda RS, Erdinc AE, Dandajenac TC and Tarisai C. Profile changes of patients treated with and without premolar extractions. Am J Orthod Dentofac Orthop. 2007;132:324-31.
40. Sharmaa JN. Skeletal and soft tissue point A and B changes following orthodontic treatment of nepalese Class I bimaxillary protrusive patients. Angle Orthod. 2010;80:91-6.

41. Zierhut EC, Joondeph DR, Artun J and Little RM. Long-term profile changes associated with successfully treated extraction and nonextraction Class II division 1 malocclusions. Angle Orthod. 2000; 70: 208-19.

42. Aydemi H, Dalci ON, Altug AT, and Memikoglu UT. The effects of tooth extraction and nonextraction on the soft tissue profile in patients with class II division 2 malocclusion.. Turkish J Orthod. 2014; 27: 63-9.

43. Kocadereli Il. Changes in soft tissue profile after orthodontic treatment with and without extractions. Am J Orthod Dentofac Orthop. 2002; 122: 67-72.

44. Xu TM, Lui Y, Yang MZ and Huang W. Comparision of extraction versus nonextraction orthodontic treatment outcomes for borderline Chinese patients. Am J Orthod Dentofacial Orthop. 2006;129:672-7.

45. Konstantonis D. The impact of extraction vs nonextraction treatment on soft tissue changes in Class I borderline malocclusions. Angle Orthod. 2012; 82:209-17.

46. Yanga H, Nahmb DS and Baekc SH. Which Hard and Soft Tissue Factors Relate with the Amount of Buccal Corridor Space during Smiling? Angle Orthod. 2008; 78: 5-11.

47. Grover N, Kapoor DN, Verma S and Bharadwaj P. Smile analysis in different facial patterns and its correlation with underlying hard tissues.. Progress in Orthodontics. 2015;16:28.

48. Suh YJ, Nahm DS, Choi JY, and Baek SH. Differential diagnosis for inappropriate upper incisal display during posed smile: Contribution of soft tissue and underlying hard tissue. J Craniofac Surg. 2009;20:2006-12

49. Rai D, Janardhanam P and Rai A. Esthetic factors of smile in vertical dimensions: A comparative evaluation. $\mathbf{J}$ Indian Orthod Soc 2015;49:25-31.

50. Miron H, Calderon S, and Allona D. Upper lip changes and gingival exposure on smiling: Vertical dimension analysis. Am J Orthod Dentofac Orthop. 2012; 141:87-93.

51. Garber DA and Salama MA. The aesthetic smile: Diagnosis and treatment. Periodontol 2000. 1996; 11:18-28.

52. Peck S, Peck L and Kataja M. The gingival smile line. Angle Orthod. 1992; 62: 91-100.

53. Silberberg N, Goldstein M and Smidt. Excessive gingival display- etiology, diagnosis, and treatment modalities. Quintessence Int. 2009; 40: 809-18.

54. Cordato M. Variation in torque expression. Am J Orthod Dentofacial Orthop. 2004; 126(1):18A. 